\title{
A Geodesign Approach for Using Spatial Indicators in Land-use Planning
}

\author{
Andrea Matta ${ }^{1, *}$, Matteo Serra ${ }^{2}$ \\ ${ }^{1}$ Department of Civil and Environmental Engineer, University of Cagliari, Italy \\ ${ }^{2}$ Department of Architecture, University of Cagliari, Italy
}

Copyright $\mathrm{O} 2016$ by authors, all rights reserved. Authors agree that this article remains permanently open access under the terms of the Creative Commons Attribution License 4.0 International License

\begin{abstract}
This paper presents an original approach to Strategic Environmental Assessment (SEA) for supporting decision-making processes in Local Land-Use Planning (LLUP) which integrates a set of frameworks and methodologies into technologies based on the use of Geographic Information. The technologies embrace the domain of Planning Support Systems (PSS), whose architecture is based on the Geodesign framework. The structure of the Planning Support System includes spatial indicators frameworks rooted on the Driving Force-Pressure-State-Impact-Response (DPSIR) framework. The spatial DPSIR model allows dealing with common issues in spatial planning, such as collaborative and participative decision-making processes, informed alternative design, real-time impact assessment and environmental reporting. Furthermore, the planning support system may foster the widespread diffusion of innovations in the planning domain reeling on the availability of Spatial Data Infrastructures. The study aims at investigating the efficiency of this approach integrated into SEA-LLUP based on the results of a case study developed in Sardinia (Italy).
\end{abstract}

Keywords Planning Support System, Geodesign, DPSIR, Spatial Indicators, Land-use, Strategic Environmental Assessment

\section{Introduction}

The sprawl of the cities and the urbanization processes have gobbled up a big amount of rural and natural areas, jeopardising the quality of environmental resources $[1,2]$. Indeed, the evaluation process of the consumption of resources is a current challenge for environmental scientists and planners, who have to deal with the loss of natural capital and the general preservation of well-being for the future generations [3]. Urban development is usually related to the conversion of natural areas, whose ownership may be public or private. Often, the set of policies that regulate land-use and influences the rights of private landowners is oriented towards preserving natural areas and limiting the urbanization processes. By contrast, often landowners aim to achieve their advantage through specific actions, consuming local resources. The sum of these actions produces a range of cumulative effects on the environment that have to be considered in the decision-making stages, through specific plans, rules and policies. These phenomena led to producing several threats for the environment, from the local to the global scale, such as erosion and desertification, loss of biodiversity, climate changes and flooding [4].

The concept of sustainability concerns the "development that meets the needs of the present without compromising the ability of future generations to meet their own needs" [5]. Indeed, sustainable development aims to ensure an adequate degree of quality of the resources, their accessibility and their availability for the future generations.

This general statement needs to be translated into policies and plans for supporting concrete applications. Jepson [6] pointed out that sustainability and planning are inextricably linked, in order to create a system to "protect the natural environment, meantime the economy has to be developed and the equity achieved".

In the last decades, the European Union has proposed a range of policies with the aim of integrating environmental considerations into projects, plans and programmes for protecting the environment. The Environmental Impact Assessment (EIA, Directive 85/337/EEC) and the SEA (Directive 2001/42/EC) directives are two of such policies that put into effect the European Union' objectives regarding the environmental preservation.

The SEA Directive, in particular, is oriented towards integrating environmental considerations into plans and programmes with the purpose of creating an informed process for supporting plan-making. In many European countries, SEA is a mandatory and an ongoing procedure applied at the national, the regional and the local levels [7]. The SEA has been implemented into the Italian Planning System through the Legislative Decree 152/2006 and it is intertwined with the plan-making processes. In Sardinia, the 
SEA is a mandatory procedure for Municipal Master Plans (MMP). The MMP is the most important document for managing Local Land-Use Planning (LLUP), in order to ensure the sustainable development of the territory in compliance with the Regional Landscape Plan (RLP) of the Sardinia Region. Indeed, the RLP is based on a range of rules and principles of protecting the environment, limiting the fragmentation of landscape. These general environment-oriented conventions should be taken into account by the Municipal Master Plan, during the adjustment process to the RLP, through specific methods for supporting the land-use management. Despite the fact that the adjustment process of the MMP to the RLP has to be concluded within one year of approval of the RLP for all the municipalities, only a few MMPs have been revised until recently [35] and a range of difficulties are still presented [21].

In the light of the above premises, the paper is organized as follows. The first part introduces current pitfalls and weaknesses in spatial planning, focusing on the integration of the European Directives and innovations in planning practices. The second section illustrates a possible way of dealing with these issues, through innovative methodologies and technological innovations. The third part demonstrates how to operatively integrate this innovative approach to planning for filling the gap between research and practice, through a case study based on SEA-LLUP procedures in Sardinia (Italy). Finally, the conclusions highlight the results of the workshop and possible further research.

\section{Current Barriers for Integrating Innovations in Spatial Planning}

The intrinsic complexity of Land-Use Planning concerns a range of activities for managing the use of land in compliance with future planning objectives. The current innovation in computer-aided planning and accessibility to (geographic) data is fostering breakthroughs in decision-making [8]. Recently, the integration of European policies into the Italian National legal framework has promoted an environmental strategic approach to spatial planning. Despite these environment-oriented developments and the growth of the Information and Communication Technology (ICT) domain, a fruitful implementation in planning practices seems to be far from complete.

\subsection{The INSPIRE Directive}

The integration of the INSPIRE Directive (2007/2/EC) into the legal framework of European member states, promotes the creation and use of Spatial Data Infrastructures (SDIs) to assist in formulating and integrating Community environmental policies across Europe. The concept of SDI arose in 1993 by the U.S. National Research Council, in order to guarantee the accessibility to Geographic Information (GI) for potential users. The SDIs encompasses a range of key elements (e.g. metadata to catalogue spatial data through a range of thematic attributes and, spatial data themes and services) and implementation rules for guaranteeing the diffusion of GI in a transboundary context. Despite the wealth of interoperable services and the public access to GI, provided by the SDIs, is offering opportunities for professional users to innovate spatial planning practices [10], a fruitful integration into decision-making processes is still limited [9]. In Italy, several Regional Authorities have built their own INSPIRE-compliant SDI for supporting the management and planning of the territory. The Region of Sardinia developed the Sardinian Regional SDI (SRSDI) with the aim of sharing data and services to all web users, via download or network services. The SRSDI offers more than 300 spatial data and services which can be used for supporting Local Land-Use Planning activities.

Despite the importance of SDIs is evident at the Regional at the Local level, their efficiency in strategic planning and decision-making is still limited [11]. Indeed, the breakthroughs in the integration of SDIs into spatial planning processes, contrast with a range of pitfalls, such as incompatible and inconsistent spatial databases and limited accessibility to GI [36].

\subsection{An Environment-oriented Planning Approach}

The research on Strategic Environmental Assessment (SEA) effectiveness for evaluating the impacts of PPPs (Policies, Plans and Programmes) on the environment encompasses a wide range of scientific literature. SEA (Directive 2001/42/EC) and the Environmental Impact Assessment (EIA, Directive 85/337/EEC amended in 2014 by DIRECTIVE 2014/52/EU) have been developed as environmentally oriented approaches with the aim of integrating environmental concerns in decision-making processes [12]. SEA is a procedure inextricably linked with decision-making processes, which integrates the sustainable development principles into PPPs [13, 14]. Tetlow and Hanusch [15] pointed out that despite the benefits produced by the application of the SEA in planning processes $[16,17$, 18] different pitfalls arose from the evaluation of its performance. One of these concerns the poor capacity of the SEA procedure to generate informed alternatives for supporting the decision-making process $[18,19]$. In turn, the evaluation process of the alternatives' influence on the environment may be inadequate [16] to support the scenarios comparison for identifying the preferable planning solution. Further pitfalls concern the scarce influence and efficiency of monitoring programmes and public participation into plan-making phases $[13,20]$. As a matter of fact, the efficiency of the SEA in informing decision-making processes and LLUP is still limited [6]. Emerging methodologies, such as the Geodesign framework and computer-aided innovations such as Planning Support Systems (PSSs), may contribute to filling the gap between current SEA goals and their fruitful integration in planning practices [21]. 
1. How should the landscape be described?

2. How do the landscape operate?

3. Is the landscape working well?

4. How might the landscape be altered?

5. What differences might the changes cause?

6. Should the landscape be changed?

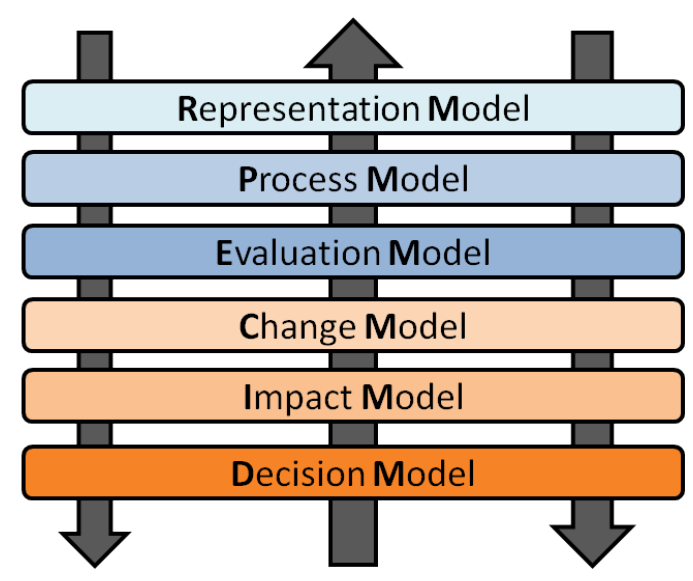

Figure 1. The Geodesign Models (Source: Author)

\section{Innovations and Methodologies for Supporting LLUP}

\subsection{The Geodesign Methodology}

Geodesign is an emerging methodological approach to planning and design that encompasses representation, analysis, design and impact assessment of the geographical space, through the participation of different stakeholders and professionals to decision-making. The Geodesign framework (GDF) may be able to bring innovation in spatial planning across different spatial scales [22], and address the current issues in the SEA procedures [10]. The GDF consists in six interactive models that operate for offering an innovative structure for dealing with planning processes (Fig. 1). The Representation Model (RM) describes the environmental system in an attempt to bring a fruitful comprehension of the geographic space on which the Geodesign team operates. In turn, the Process Model (PM) and the Evaluation Model (EM), generate information to investigate the dynamics of environmental phenomena and manage territorial weaknesses and strengths for addressing development strategies. The Change Model (CM), takes into account the knowledge base generated through the first three models to design scenarios, including solutions and alternatives. Finally, the influence of the design activities on the environment is evaluated through the Impact Model (IM) with the aim of producing information and supporting suitable decision processes (Decision Model - DM). The implementation of the GDF may occur in different ways which can be supported by Planning Support Systems. An early attempt to demonstrate the efficiency of Geodesign-based PSS architecture for supporting LLUP was carried out by Campagna and Matta [10]. An early approach to structured information flow integrated into LLUP procedures was carried out through a spatial indicators framework, claiming the need for further research.

\subsection{The Planning Support System Architecture}

The term Planning Support System (PSS) is not new. It was coined by Harris in 1989 [23] for describing an architecture coupling a range of computer-based methods and models into an integrated system in order to support planning functions. This general definition was further developed, integrating more operatively the early definition of PSS as a system which couples Geographic Information System (GIS), and non-GIS data, spatial models and geo-tools for dealing with the complexity of planning procedures [24, 25]. The geo-tools nested in the PSS architecture concern the representation, management and analysis of spatial data across different spatial scale and time, through a user-friendly interface, providing planners support to deal with the complexity of planning procedures. These geo-tools include the Land Suitability Analysis (LSA), the sketch planning and the real impact assessment, the scenario comparison and the report production. The LSA is a GIS-application which allows analyzing the geographic space with the aim of locating predetermined uses of land according to specific parameters [26]. It provides the base on which to generate design activities for future territorial developments. Sketch planning can be considered part of the planning process and makes the planners able to explore planning issues for producing alternatives and scenarios [27]. Sketch planning offers opportunities to enhance spatial modeling fostering participation and collaborative processes to decision-making steps. The real-time impact assessment concerns the influence of the alternatives on the environment through a set of spatial indicators, enclosed in a dynamic electronic dashboard. The indicators are able to support the communication of complex phenomena in a simple way [28, 29]. Indicators show the value of specific parameters used during the representation, analysis and decision procedures, fostering a collaborative and participative decision-making processes since the early plan-making phases. The PSS architecture makes available to users a range of indicators that realize the integration of spatial data into planning processes through structured frameworks. The production of predefined reports allows generating a transparent decision-making process, including maps, data, indicators and formulae, used during the plan-making phases. The role of spatial indicators in the PSS architecture is currently 
undefined. Although there are predefined indicators that show a set of parameters that influence the design and the impact assessment, there is a lack of relationship among them and a non-structured information flow across the geo-tools. For this reason, the fruitful integration of a structured spatial indicators framework into the PSS architecture can be considered far from being achieved.

\subsection{A Spatial Indicators Framework}

The role of indicators in planning processes concerns different phases and tasks. Indicators may show the current territorial situation and how specific environmental and urban parameters change during the design activities. In addition, they support the monitoring program for evaluating the influence of the design activities on the environment. According to the requirements of the regional planning regulations and the SEA-LLUP guidelines in Sardinia, a set of structured indicators have to be implemented in the Environmental Report (ER) for integrating impact assessment and monitoring program.

The most important indicators frameworks used at the international and the national level are based on the concept of causal chains, where the output of each component of the framework feeds the other in a loop [29]. An indicator framework based on the causal chain theory, may help to organize the cause-effect relationships among indicators, in order to provide reliable information about interdependencies between human societies and the natural environment [30].

The Driving-Force-Pressure-State-Impact-Response (DPSIR) is a casual-based indicators framework able to support the decision-making process [29]. The DPSIR is often used to stimulate the societal responses related to the environmental problems, in order to preserve the resources for the future generation, according to the sustainability of development principles [31]. The framework is based on five components that support the comprehension of phenomena and fills the gap between the real world and its representation. These components interact in a loop (Fig. 2): (i) Drivers (D), (ii) Pressures (P), (iii) States (S), (iv) Impacts (I) and (v) Responses (R). The first three components represent the "causes" that generate the "problems", encompassed in the fourth component. In turn, the fifth component deals with the problem putting the basis for the "solution(s)" [32].

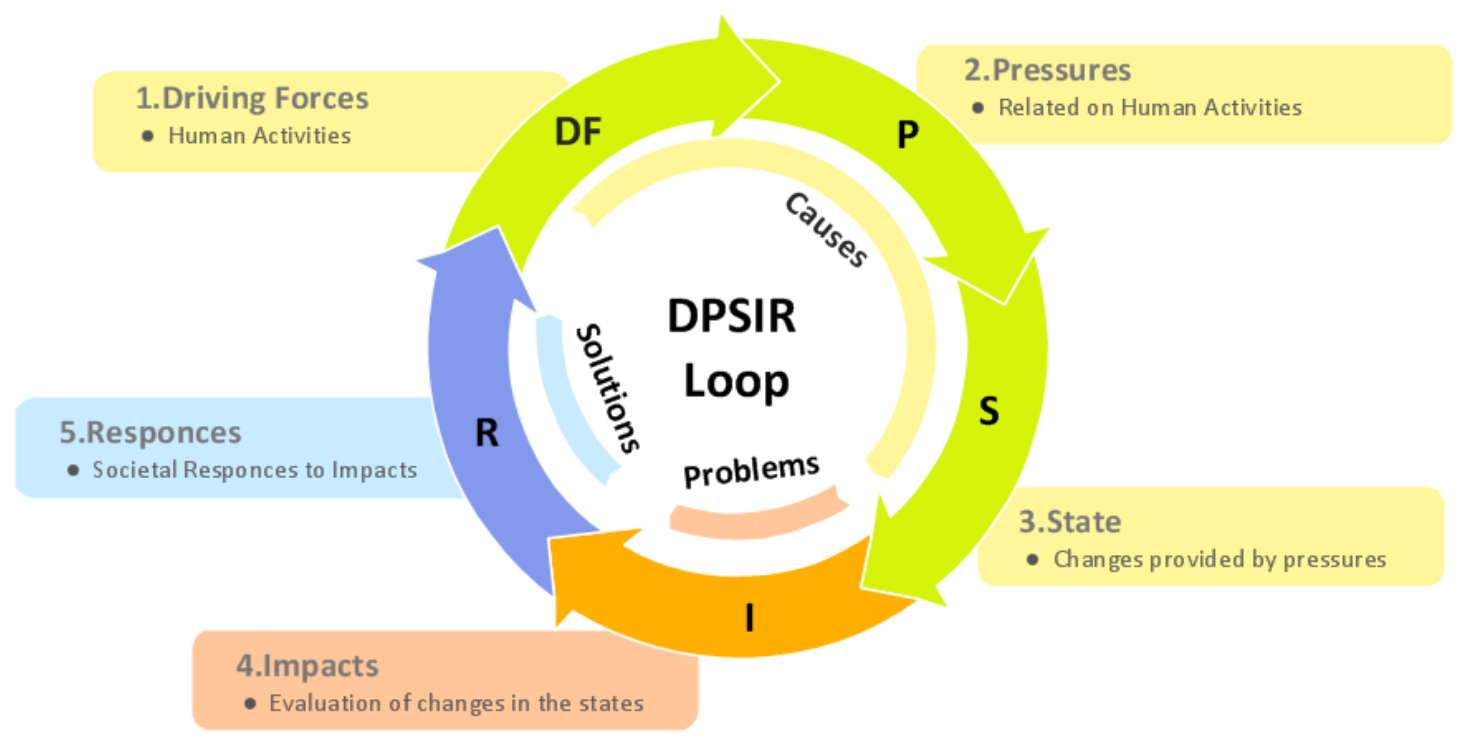

Figure 2. The DPSIR framework (Source: Author)

The Environmental Protection Agency (EPA), provides generic relationships among the DPSIR components for supporting the integration of the framework into spatial planning. These relationships drove the connections between the DPSIR framework with the GDF, as argued by Campagna and Matta [10] (Fig. 3). The iterations of the DPSIR loop are intertwined with the GDF models: the first loop concerns the analysis of the current territorial conditions (RM, PM and EM), such as the representation and analyses of current urban-environment phenomena and general proposals for producing future development strategies of the territory. The information and spatial data produced in this early phase can be considered the base on which operatively modelling the geographic space in compliance with the planning objectives and the sustainable resource consumption (CM, IM and DM) (Fig. 3).

Nevertheless, the research on sDPSIR for supporting LLUP concerns just a few practical case studies [10, 33, 31]. 


\section{DPSIR framework}

\section{Geodesign framework}

1a Driving Forces

1b Pressures

1 Representation Model

을

1c States

2 Process Model

1d Impacts

3 Evaluation Model

1e Responses

2a Driving Forces

4 Change Model

$2 b$ Pressures

융

$2 c$ States

5 Impact Model

2d Impacts

2e Responses

Figure 3. The relationships between DPSIR framework and GDF

The fig. 3 shows an early integration of the sDPSIR framework into SEA-LLUP, implemented in 2014 [10]. In order to extend the investigation into the role of spatial indicators in LLUP practices, a case study that concerns a practical workshop in the municipality of Gonnesa (Sardinia, ITALY) is proposed in the next paragraphs.

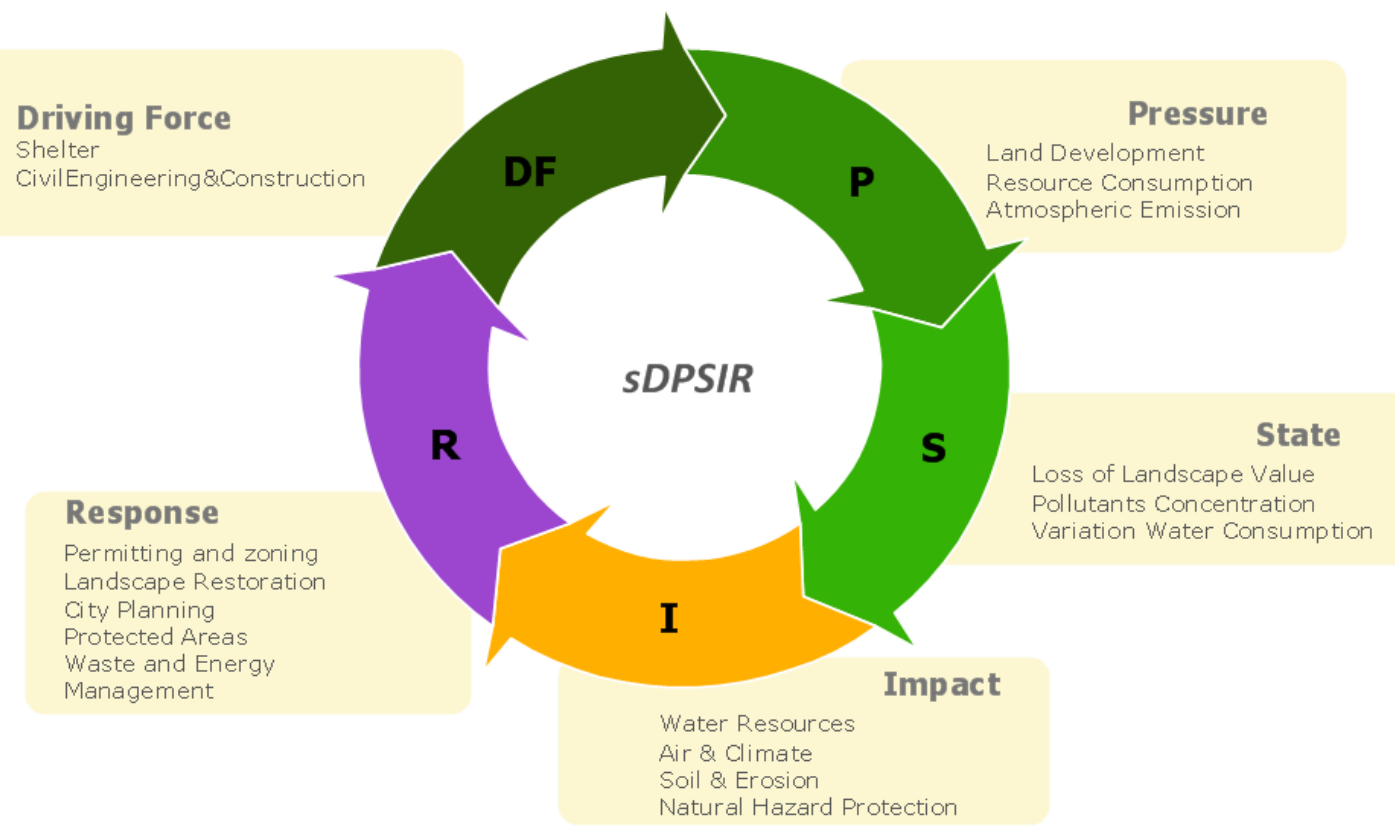

Figure 4. An early integration of the sDPSIR into SEA-LLUP 


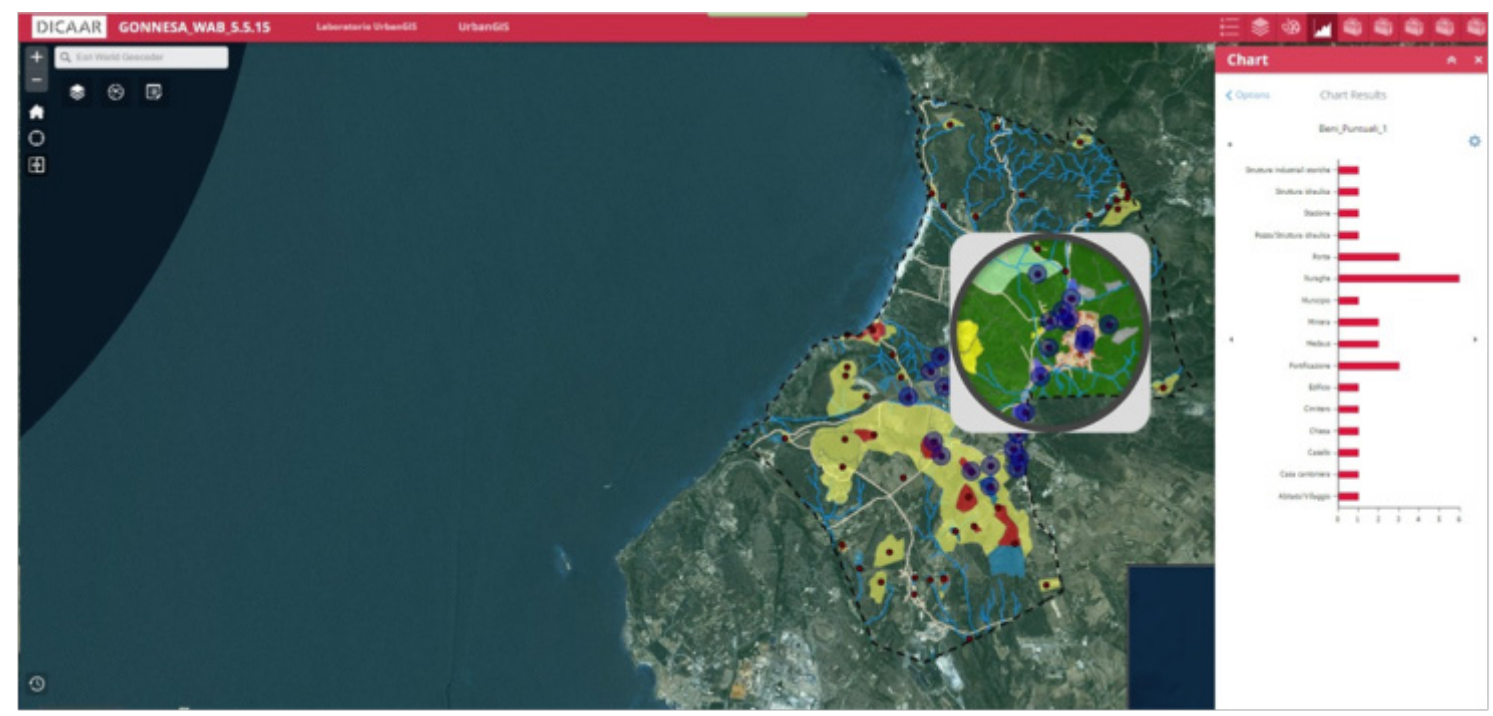

Figure 5. The Web-based PSS architecture for representing and analysing the DPS components

\section{A SEA-LLUP Workshop for Integrating Innovations in Practices}

\subsection{The sDPSIR Integrated into a Geodesign-based PSS Architecture}

The case study concerns a workshop on LLUP, realized by the UrbanGIS Lab of the University of Cagliari, in collaboration with the local authority of the municipality of Gonnesa. It was carried out in compliance with the COST TU 1002 guidelines for innovating spatial planning practices [37]. The group of participants to the workshop (Workshop Users - WUs) was composed by a range of professionals, researchers, and local administrators, with the aim of making value of their experiences for comparing current practices and the proposed methodologies and innovations.

The workshop aims to investigate how technological innovations and emerging methodologies may influence current planning practices. The goal was to analyse the process of location, design and evaluation of a new touristic area in the municipality area. This paper takes into account the influence of these innovations in spatial planning for demonstrating the role of GI and spatial indicators for supporting collaborative decision-making.

\subsubsection{Representation and Process Models}

The first phase of the workshop was oriented both to represent the municipal territory and to perform spatial analyses through the use of spatial data, made available by the Regional SDI (SRSDI) and the public administration. In a broad sense, the WUs were able to compare the current system for sharing and represent spatial and non-spatial data of the local administration with the innovative approach based on a Web-architecture. In this phase, a Web-Based PSS was used to generate information and integrate the Representation Model and the Process Model into practice (Fig. 5). The Web-based PSS is an architecture that makes available a range of thematic maps, such as the current land-uses, hydrogeological hazards and cultural and historical goods, and a range of nested geo-tools for performing spatial analyses (e.g. the number of historical sites in a specific portion of the area). The outputs of these analyses are shown through spatial indicators, representing the first three component of the sDPSIR: DF, P and S. Indeed, the values of the indicators represent the Driving Forces that dominate the urban phenomena (i.e. number of inhabitants, residential volumes and areas) and produce Pressures on the environment (i.e. soil consumption, costs). In turn, the PM, through the geo-tools, provides the information for feeding the State component (i.e. loss of natural landscape, production of goods and services).

\subsubsection{Evaluation Model}

The third phase of the workshop is based on the management and the analyses of the knowledge generated through the RM and PM. Indeed, the first three components of the sDPSIR depict the "causes" of the "problem" that in turn, generate the Impacts on the environment. This information flow allows establishing both the environmental questions and the development goals for the territory. These issues can be dealt with a range of proposals that may arise from different groups of stakeholders, related to their own purposes, such as environmental and socio-economic questions. Nevertheless, if not adequately supported by methodologies and analysis tools, the process of combination and analyses of different planning goals may be too complex. For this reason, the EM supports the process of evaluation of these purposes, driving the design of future suitable alternatives.

The EM may enclose both mitigation actions for reducing the environmental impact of current urban phenomena and suitable proposals for new design and developments. This planning task is supported by the Land Suitability Analysis (LSA) tool with the aim of generating a range of suitability maps [26] and fostering the negotiation among stakeholders, concerning different plan solutions. 


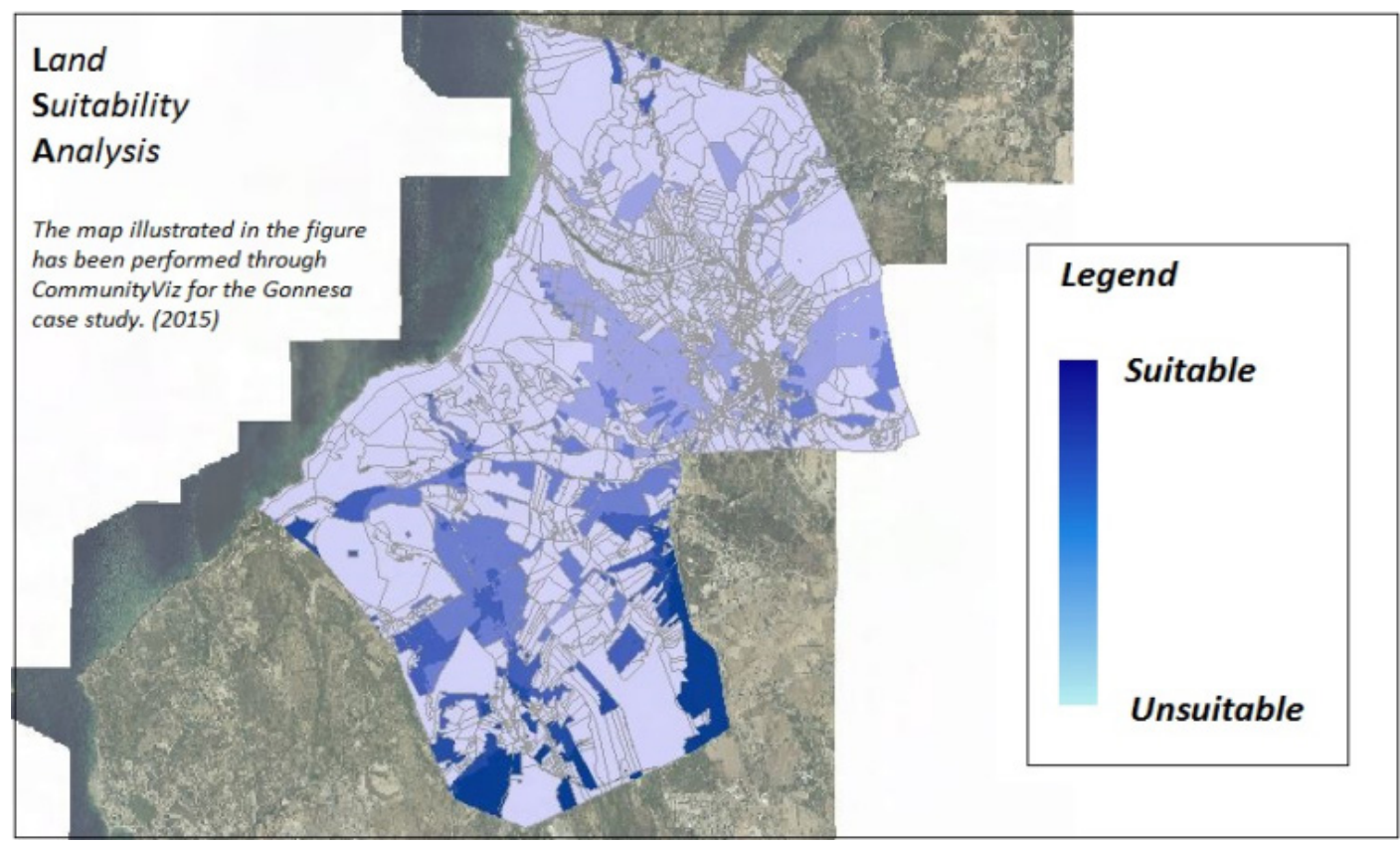

Figure 6. An Evaluation map for supporting the development of future strategies

The LSA tool allows combining a wide range of spatial data for producing maps that represent the result of a range of spatial analyses. The maps, namely suitability maps, concern specific urban and environmental phenomena that should be analyzed for defining the alternatives in the CM. The spatial data are combined through different spatial operations, such as weighted selections, that generate a range of criteria, which value can be changed during the negotiation phase. These variations produce real-time changes in the suitability maps, offering different planning solutions. The maps may represent, with a different colour ramp, for instance, the suitability rate of adequate sites for the planning purposes. The lightest colours represent the lowest suitability rate, where the combination of selected criteria defines the non-adequate areas. The darkest colours concern the highest suitability rate, representing the adequate areas for the proposed planning goal (Fig. 6).

The WUs were able to produce real-time map variations, thanks to a set of dynamic weighted attributes (e.i. proximity to the main roads), informing the discussion regard their own purposes for future territorial developments (Fig. 6).

The evaluation maps represent the location of suitability areas on the territory for a specific planning goal, in order to deal with the "causes of the problems", depicted through the Impact component of the DPSIR framework. The group of spatial indicators related to the Impact, show the influence of the design activities on the environment, through a dynamic dashboard enclosed in the PSS architecture. It can be argued that the impact component embraces the base-knowledge of the territory both for supporting planners in design activities and for driving suitable planning solutions, in compliance with participative and collaborative planning procedures.

\subsubsection{Change and Impact Model}

The CM encloses the transformation of the geographical space due to the results by the design setting. The causes of the territorial metamorphosis may have different drivers, represented through the DPSI components. In order to support planners for dealing with this task, the $\mathrm{CM}$ is supported by the PSS architecture through the sketch planning tool that makes the users able to design a range of alternatives. The sketch planning is a GIS-based planning tool that allows putting into effect abstract concepts for evaluating their effect on the environment referring to a specific planning objective [34]. The WUs were able to negotiate a range of alternatives based on the evaluation maps, for generating different scenarios. Each design solution is related to a real-time variation of the spatial indicators that foster the comprehension of the design influence on different domains (e.g. environmental, social and economic).

On the one hand, the sketch planning activities may support the design of mitigation actions that arose from the evaluation of the territorial phenomena originated in the preliminary analysis phases (e.g. environmental problem). On the other hand, the design concerns proposals for the municipal territory in order to support development strategies (e.g. a new touristic area). For this reason, the CM operates for dealing with the "Responses" that arise from the DPSI components, feeding back the framework with new Drivers and Pressures. It can be argued that, the CM both complete the first loop of the sDPSIR framework and put the basis for the second one (Fig. 3). Indeed, the spatial indicators are able to show how the Driving Forces may create new Pressures on the environment leading to changes in the State. For this reason, the Impacts change, in compliance with the new information generated during the design activities. 


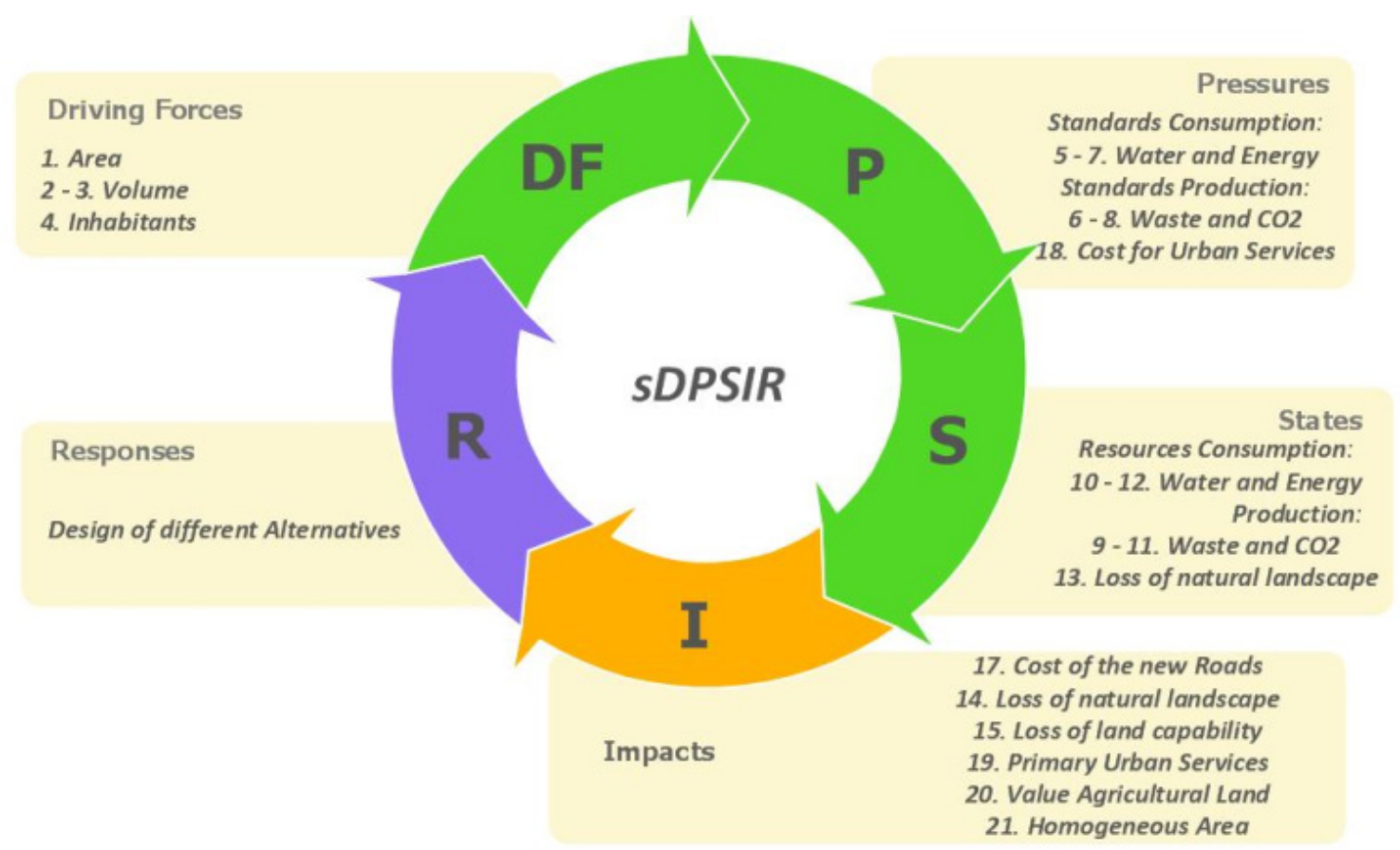

Figure 7. How the sDPSIR is able to help planners to manage information during the plan-making phases

The CM and the IM operate at the same time, representing how changes in the geographical space are instantly related to a variation of different parameters. The DPSIR framework nested in the PSS architecture is able to support the communication of information to stakeholders in a simple way, improving the comprehension of how these alternatives influence the environment and providing a structure for organising complex information flow along the decision-making procedures.

\subsubsection{Decision Model}

The different scenarios and the relative environmental impacts show how the decision-making process may influence the environment and the citizen' well-being. In order to generate a suitable response to the planning goal, the scenarios should be compared and analyzed. The process of comparison may lead to operating further design activities for enhancing the final design solution. This process contributed to the production of the final alternatives is in compliance with both the planning goal and the stakeholder' purposes. The "responses" generate a negotiation among stakeholders with the aim of merging the requests of sustainable resource consumption from the SEA and the purposes of economic and urban growth from the local administration. The final scenario represents both how the information flow supports the decision-making process since the early phases, starting from the analysis of the current situation to the scenarios comparison, and how the sDPSIR contributes to the management of this information (Fig. 7). The DM depicts the future developments of the municipal territory in an attempt to communicate in a simple way the intrinsic complexity on which the decision-making process is based.

\section{Conclusions}

Land-Use planning encompasses a wide range of methodologies, technologies and groups of people, such as politicians, citizens and stakeholders, in order to orchestrate the uses of lands in compliance with sustainable development goals [38]

In this context, the paper presents an innovative approach to Strategic Environmental Assessment of a Local Land-Use Planning Support System implemented for the municipality of Gonnesa (Sardinia, Italy). The case study shows how structured GI frameworks, integrated into SEA-LLUP procedures, fulfil an important role in supporting decision-making processes.

The PSS architecture allow the integration of the GI in the Sardinian planning context, and may contribute to dealing with the complexity of planning activities in all the plan-making phases, such as the creation of the base-knowledge for generating an informed design of alternatives and for supporting the negotiation among stakeholders.

The sDPSIR framework nested in the PSS architecture provides a structure for developing the cause-effect relationships on which the planning goals are built. This causal chain supports a collaborative and transparent planning process since the early plan-making phases. Indeed, it allows generating a shared comprehension of the territorial context making available dynamic data that change thanks to a continuous integration of information from stakeholders. In addition, this base-knowledge becomes the source for addressing informed alternatives' design and supporting the monitoring of their influence on the environment. For this reason, this innovative approach may allow emphasising the 
role of the GI technologies across the plan-making phases in the Sardinia planning context.

The workshop was enriched by a range of questionnaires for assessing the WUs' opinions on this innovative approach to SEA-LLUP. The participants pointed out that the PSS architecture, and in particular the management of the information flow across the decision-making, may be considered a reliable plan-making support. Moreover, the PSS architecture allows not only of dealing with the request of the SEA-LLUP procedures both for integrating informed environment-oriented procedures into practice and monitoring their impact, but also of fostering a transparent and collaborative decision-making process, from the early plan-making phases until the final decision, supporting a shared comprehension of the planning processes among stakeholders and decision-makers.

In conclusion, this PSS can be considered an innovative approach that contributes to the integration of the Geodesign framework into planning activities, such as in the representation and analysis of the current territorial context, in the design of plan alternatives, in the support of the participation processes and in the evaluation of the most suitable development scenario. The sDPSIR framework may contribute to putting into effect the GDF models in practice, supporting the planning process through an informed design of alternatives and a real-time impact evaluation across the decision-making phases.

However, the results illustrated in the paper concern an early approach to planning practices, for this reason, further case studies may contribute to ameliorating the architecture for dealing with the complexity of the plan-making activities.

\section{Acknowledgements}

The work presented in this paper was developed in the framework of the International $\mathrm{PhD}$ in Environmental Science and Engineering at the University of Cagliari. We would like to thank Matteo Serra for his efforts on organizing the workshop and the Web-based PSS architecture.

\section{REFERENCES}

[1] Wang, H., Shen, Q., and Tang, B. S. (2014, January). A Review of Planning Support Systems for Urban Land Use Planning. In Proceedings of the 17th International Symposium on Advancement of Construction Management and Real Estate (pp. 233-248). Springer Berlin Heidelberg.

[2] Kötter, T., and Friesecke, F. (2005, October). Urbanization and Megacities-The Challenge of the 21st Century. In The 6th Open Meeting of the Human Dimensions of Global Environmental Change Research Community, University of Bonn, Germany (pp. 9-13).

[3] Olewiler, N. (2006). Environmental sustainability for urban areas: The role of natural capital indicators. Cities, 23(3), 184-195.

[4] Caparros-Midwood, D., Barr, S., and Dawson, R. (2015). Optimized spatial planning to meet long term urban sustainability objectives. Computers, Environment and Urban Systems, 54, 154-164.

[5] Brundtland, G., Khalid, M., Agnelli, S., Al-Athel, S., Chidzero, B., Fadika, L., ... and Okita, S. (1987). Our Common Future ('Brundtland report').

[6] Jepson, E. J. (2001). Sustainability and planning: diverse concepts and close associations. Journal of planning literature, 15(4), 499-510.

[7] Zoppi, C., Lai, S., (2008), "Strategic Environmental Assessment of a Landscape Plan: A Case Study Concerning Sardinia, an Italian Region" in: European Regional Science Association, 48th Congress, Liverpool, Regno Unito, presented in the Session 10.Y: Sustainability and environmental management.

[8] Couclelis, H. (2005). "Where has the future gone?" Rethinking the role of integrated land-use models in spatial planning. Environment and planning A, 37(8), 1353.

[9] Citroen, C. L. (2011). The role of information in strategic decision-making. International Journal of Information Management, 31(6), 493-501.

[10] Campagna, M., and Matta, A., (2014, August). Geoinformation technologies in sustainable spatial planning: a Geodesign approach to local land-use planning. In Second International Conference on Remote Sensing and Geoinformation of the Environment (RSCy2014) (pp. 92290T-92290T). International Society for Optics and Photonics.

[11] Craglia, M., and Campagna, M. (2009). Advanced regional spatial data infrastructures in Europe. Luxembourg: Office for official publications of the European Communities.

[12] Abaza, H., Bisset, R., and Sadler, B. (2004). Environmental impact assessment and strategic environmental assessment: towards an integrated approach. UNEP/Earthprint.

[13] Fischer, T. B. (2010). The theory and practice of strategic environmental assessment: towards a more systematic approach. Routledge.

[14] Geneletti, D., Bagli, S., Napolitano, P., and Pistocchi, A. (2007). Spatial decision support for strategic environmental assessment of land use plans. A case study in southern Italy. Environmental Impact Assessment Review, 27(5), 408-423.

[15] Tetlow, F., M., and Hanusch, M., (2012). Strategic environmental assessment: the state of the art. Impact Assessment and Project Appraisal, 30(1), 15-24.

[16] Weiland, U., (2010), "Strategic environmental assessment in Germany-practice and open questions." Environmental Impact Assessment Review 30.3 211-217.

[17] Therivel, R., Christian, G., Craig, C., Grinham, R., Mackins, D., Smith, J., and Yamane, M. (2009). Sustainability-focused impact assessment: English experiences. Impact Assessment and Project Appraisal, 27(2), 155-168.

[18] West, C., Borzuchowska, J., and Ferreira, A., 2011. SEA application in the UK, Poland and Portugal - a consultant's 
perspective. Paper presented at the IAIA Special Conference on SEA, Prague, 21-23 September.

[19] Smith, S., Richardson, J., McNab, A., and Wilson, S., (2010). Towards a more efficient and effective use of strategic environmental assessment and sustainability appraisal in spatial planning: final report. London: Scott Wilson Ltd for the Department of Communities and Local Government.

[20] Hanusch, M., and Glasson, J. (2008). Much ado about SEA/SA monitoring: The performance of English Regional Spatial Strategies, and some German comparisons. Environmental Impact Assessment Review, 28(8), 601-617

[21] Campagna, M., and Di Cesare, E. A. (2016). Geodesign: Lost in Regulations (and in Practice). In Smart Energy in the Smart City (pp. 307-327). Springer International Publishing.

[22] Steinitz, C. (2012), A Framework for Geodesign. Changing Geography by Design, Esri Press, and Redlands.

[23] Harris, B. (1989). Beyond geographic information systems. Journal of the American Planning Association, 55(1), 85-90.

[24] Klosterman, R. E. (1997). Planning support systems: a new perspective on computer-aided planning. Journal of Planning education and research, 17(1), 45-54.

[25] Geertman, S., and Stillwell, J. (2004). Planning support systems: an inventory of current practice. Computers, Environment and Urban Systems, 28(4), 291-310.

[26] Malczewski, J. (2004). GIS-based land-use suitability analysis: a critical overview. Progress in planning, 62(1), 3-65.

[27] Heppenstall, A. J., Crooks, A. T., See, L. M., and Batty, M. (Eds.). (2011). Agent-based models of geographical systems. Springer Science and Business Media.

[28] Hammond, A., and World Resources Institute. (1995). Environmental indicators: a systematic approach to measuring and reporting on environmental policy performance in the context of sustainable development (No. 333.7/H225). Washington, DC: World Resources Institute.

[29] Smeets, E., and Weterings, R. (1999). Environmental indicators: Typology and overview (p. 19). Copenhagen: European Environment Agency.

[30] Niemeijer, D., and de Groot, R. S. (2008). Framing environmental indicators: moving from causal chains to causal networks. Environment, Development and Sustainability, 10(1), 89-106.

[31] Carr, E. R., Wingard, P. M., Yorty, S. c., Thompson, M. C., Jensen, N. K., and Roberson, J., 2007, "Applying DPSIR to Sustainable Development." International Journal of Sustainable Development and World Ecology, 14: 543-555.

[32] Giupponi, C. (2002, November). From the DPSIR reporting framework to a system for a dynamic and integrated decision making process. In MULINO International Conference on "Policies and tools for sustainable water management in the EU. Venice, Italy.

[33] Apitz, S. E. (2007). Conceptual frameworks to balance ecosystem and security goals. In Managing Critical Infrastructure Risks (pp. 147-173). Springer Netherlands.

[34] Harris, B. (2001). Sketch planning: Systematic methods in planning and its support. Planning Support Systems: Integrating Geographic Information Systems, Models, and Visualization Tools, 59-80.

[35] De Montis, A., Ledda, A., Caschili, S., Ganciu, A., and Barra, M. (2014). SEA effectiveness for landscape and master planning: An investigation in Sardinia. Environmental Impact Assessment Review, 47, 1-13.

[36] Craglia, M., and Annoni, A. (2007). INSPIRE: An innovative approach to the development of spatial data infrastructures in Europe. Research and Theory in Advancing Spatial Data Infrastructure Concepts, 93-105.

[37] te Brömmelstroet, M., Silva, C., and Bertolini, L. (Eds.). (2014). Assessing usability of accessibility instruments. COST office.

[38] Couclelis, H. (2005). “Where has the future gone?” Rethinking the role of integrated land-use models in spatial planning. Environment and planning A, 37(8), 1353-1371. 